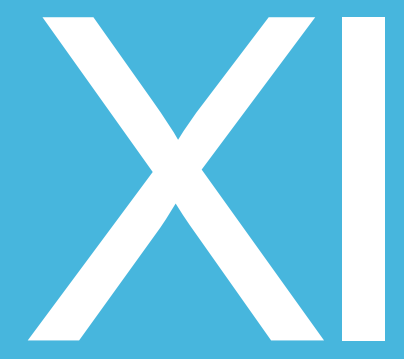

\title{
MENSAJE DE LA IMAGEN VISUAL EN LAS CLASES DE LOS DOCENTES ADVENTISTAS
}

\section{Message of the visual image in classes of Adventist teachers}

Universidad Peruana Unión

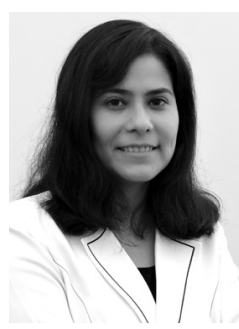

\section{Nidia Areli Montalvo Cárdenas}

Licenciada en Periodismo por la Universidad Nacional Santiago Antúnez de Mayolo (Ancash-Perú). Obtuvo un diplomado en Relaciones Públicas por la Universidad Nacional de Trujillo. Estudió la Maestría en Educación con mención en Investigación y Docencia Universitaria por la Universidad Peruana Unión (Lima-Perú). Cursó los estudios doctorales en Educación con mención en Currículo y Docencia por la Universidad Peruana Unión. Actualmente se desempeña como docente asociada de la Facultad de Ciencias Humanas y Educación en la Universidad Peruana Unión, y como editora asociada de la Oficina de Publicaciones y Difusión Cultural de la misma universidad. 


\section{Resumen}

La imagen visual es un elemento empleado como recurso para comunicar y complementar un tema de estudio en las clases de los docentes. La utilización de los recursos didácticos en el desarrollo del proceso de enseñanza-aprendizaje universitario es un componente fundamental para el desarrollo del aprendizaje significativo. Por ello, el propósito del estudio fue identificar el impacto que pueden lograr los educadores en los estudiantes receptores al percibir y visualizar diversas imágenes visuales. A través de la búsqueda y análisis de fuentes primarias y secundarias: investigaciones científicas, revistas y libros, se realizó el presente estudio que contiene un análisis de la enseñanza docente enmarcada en la misión de la Integración de la Fe en el Aprendizaje, la utilización de la imagen visual, el mensaje que transmite a los estudiantes y el impacto de los contenidos en la comunicación significativa. La investigación propone el uso coherente de la imagen como elemento comunicador de mensajes en los discursos educativos realizados en las sesiones de aprendizaje; asimismo, la reflexión personal y corporativa de los educadores adventistas sobre el empleo de diversas imágenes visuales que estén en congruencia con la filosofía educativa adventista y la cosmovisión bíblicocristiana.

Palabras clave: Comunicación significativa, imagen visual, impacto visual, Integración de la Fe en el Aprendizaje.

\section{Abstract}

The image is a visual element used as a resource to inform and complement a subject of study in classes of teachers. The use of teaching resources in the development of the teaching - learning university is essential for the development of meaningful learning component. Therefore, the purpose of the study was to identify the impact that educators can achieve receptors to perceive visual images and display various students. Through the search and analysis of primary and secondary sources: scientific research, magazines and books, the present study provides an analysis of teacher education framed in the mission of the Integrating Faith in Learning was performed using the visual image, the message conveyed to students and the impact of content in meaningful communication. The research proposes the consistent use of the image as item communicator educational discourses posts made in learning sessions; also personal and corporate reflection of Adventist educators on the use of various visual images that are consistent with the Adventist educational philosophy and biblical Christian worldview.

Keywords: Meaningful communication, visual image, visual impact, Integrating Faith in Learning. 


\section{Introducción}

En el ejercicio de sus funciones educadoras, los docentes utilizan metodologías para facilitar el cumplimiento de sus objetivos. De esta manera, tales métodos pueden incluir el uso de recursos didácticos atractivos y llamativos para los estudiantes. Entre los más utilizados se encuentran los pertenecientes a la comunicación visual. Así, las imágenes visuales, por su poder de atracción a la vista humana, se constituyen en recursos favoritos de los profesores para transmitir determinados mensajes en relación a una materia de estudio. Hasta ese punto, pareciera no existir problema alguno. No obstante, en un proceso educativo donde se comunican mensajes y se tienen propósitos establecidos (como en el caso de la educación adventista), no es suficiente usar los medios visuales, sino saber su adecuada aplicación, contextualización y el motivo por el cual los emplean.

Los educadores adventistas, al ser parte de un sistema organizado, tienen el desafío de poner sus talentos y aptitudes para contribuir con la misión de formar para esta vida y la eternidad; además de poner sus esfuerzos para hacer de la educación una tarea sencilla y redentora. Elena de White (2008) explica que "el maestro debería tener constantemente por meta la sencillez y la eficacia. Debería enseñar principalmente con ilustraciones y aun al tratar con alumnos mayores, debería tener cuidado de que sus explicaciones sean claras y sencillas. Muchos alumnos de más edad son niños en entendimiento" (p.127).

En ese sentido, los educandos de las instituciones educativas adventistas debieran, en cada sesión de aprendizaje, recibir una educación que armonice todas las facultades de su ser y acercarlo a su Creador. Pero, a veces, esta misión puede ser afectada con acciones que, aunque parezcan pequeñas o inofensivas, tienen una repercusión significativa a lo largo de sus vidas. De esa forma, la selección y utilización de imágenes visuales en las sesiones de enseñanza, a veces, puede contradecir la cosmovisión que fundamenta todo el sistema educativo adventista. $Y$ si son utilizadas con mayores criterios comunicativos, pueden ser herramientas que reafirmen el pensamiento bíblico-cristiano.

\section{Antecedentes de una educación comunicativa}

Desde su creación y primer momento de interacción con su edénico hogar, los seres humanos han percibido su entorno, dotado de formas, 
texturas, sonidos y colores, de una forma cercana; a la vez que le permitían una conexión y relación significativa. Sin embargo, en ese relacionamiento requerían comprender el mensaje que transmitía cada cosa y ser creado por Dios. Es decir, para poder decodificar correctamente lo que veían diariamente, les era necesaria la explicación proveniente de la fuente originadora de las maravillas que ellos podían observar y disfrutar. Por ello, Jehová, su Hacedor, se manifestó no solo como tal, sino como un Padre educador que iba a comunicarles y revelarles los mensajes contenidos en su obra magna. Así, el primer hogar de Adán y Eva fue también el primer centro de educación, formación e instrucción. "El jardín del Edén era el aula, la naturaleza el libro de texto, el Creador mismo era el Maestro, y los padres de la familia humana, los alumnos" (White, 2008, p. 13).

En la escuela del Edén, el Creador enseñó los diversos asuntos del saber por medio de una metodología relacional, donde la didáctica de la enseñanza estaba basada en el libro de la naturaleza. Eso significaba que la comunicación visual implícita en esta forma de educación, constituiría una herramienta útil para hacerles conocer y comprender una verdad que debían interpretar. Se identificaba la utilización de la flora y fauna, la tierra, el mar y todo lo creado como el 'texto y las imágenes' que los primeros estudiantes percibirían para aprender. Estos recursos visuales complementarían la educación de sus caracteres. White describe que los mismos serían lecciones vivas para otorgarles inagotable instrucción y deleite.

Posteriormente, luego de la entrada del pecado en la escuela y hogar del Edén, los sistemas educativos fueron reestructurados. Dios asignó un rol docente a los padres humanos, a patriarcas y profetas y a líderes estudiosos de sus verdades. La intención era otorgarles la oportunidad de contribuir con la educación de sus hijos, pero no debían olvidar que todos, educadores y estudiantes humanos, debían ser enseñados y dirigidos por Él, el verdadero Maestro. De esta manera, se esperaba que "doquiera se llevaba a cabo en Israel el plan educativo de Dios, se viera, por sus resultados, que Dios era su autor" (White, 2008, p. 26).

Pese a la gran responsabilidad dada a los seres humanos, de ser colaboradores del Creador en la educación de los hombres, muchos hogares de los israelitas desoyeron las indicaciones del cielo. En el libro "La educación", Elena de White señala que el plan educador de Dios no era respetado en su totalidad y que, por la influencia de las culturas y pueblos que los rodeaban, descuidaron las instrucciones divinas. Por consiguiente, no fueron transmitidas a las generaciones futuras. Esta situación generaría una crisis de identidad hacia la educación basada en los preceptos celestiales. 
Sin embargo, escuelas como las de los profetas en Israel llegaron a fortalecer el cimiento de prosperidad de su pueblo. Fue a causa de la comunicación significativa de los mensajes plasmados en los principios divinos y la relación dependiente con el Maestro del Cielo, que lograron forjar caracteres firmes en grandes personajes mencionados en las Sagradas Escrituras.

Aunque, a lo largo de los años, los sistemas y enfoques educativos han ido cambiando y replanteándose desde diversas perspectivas socioculturales, el sistema educativo adventista surgió con un enfoque bíblicocristiano donde todos los agentes educativos colaborarían en la restauración del hombre a su imagen primigenia. Pero, en un mundo secularizado, ¿qué repercusiones ha tenido la influencia del entorno y de qué manera ha incursionado en la vida de los adventistas? Además, ¿cómo se ha relacionado en sus acciones, incluyendo las labores educativas?

"En una época materialista y secular no es fácil desarrollar una cosmovisión cristiana" (Bouvet de Korniejczuk, 2005, p. 23). Sin duda, la influencia es tan fuerte -pero no por eso determinante- que ha derivado en la idea de una separación de la vida espiritual y la vida laboral, como en el caso de muchos docentes educadores, la insinuación de que la función educadora en la iglesia es una y en los colegios, institutos o universidades es otra. De esa forma, se ha gestado un estilo de vida híbrido, donde los educadores a veces son cristianos; otras veces, no lo son. Para Fernando Canale (2005) es importante entender que el estilo de vida es la forma cómo se vive diariamente. "Por otro lado, la forma en que vivimos cada día es la forma como somos como personas y como cristianos. Sin embargo, muchos adventistas, siguiendo una convicción cristiana generalizada, distinguen entre 'vida espiritual' y estilo de vida. De acuerdo a este punto de vista, nuestra 'vida espiritual' (vida cristiana) es diferente y no se relaciona con los asuntos comunes y sin importancia de la vida cotidiana (estilo de vida)" (p. 23).

De otro lado Bouvet de Korniejczuk (2005) citando a Byrne menciona que este critica la educación cristiana contemporánea al decir que "los docentes cristianos enseñan las asignaturas con un marco de referencia secular. Pocos docentes cristianos han aprendido a usar las implicaciones de la filosofía cristiana de la vida como está en la Biblia, como una guía directa en el proceso de enseñanza-aprendizaje" (p. 37).

Frente a ello, surgen diversas interrogantes respecto al quehacer del docente adventista en las instituciones educativas que tienen una cosmovisión cristocéntrica. Sin duda, con más de un siglo de experiencias exitosas en la 
educación de los niños y jóvenes, los principios de la educación adventista corroboran la idoneidad del modelo bíblico para la educación y formación de las personas. Pero, siempre hay aspectos que analizar y, sobretodo, reflexionar. ¿Cuán trascendentes son los medios y los contenidos en la sesión de aprendizaje? ¿Cómo influyen en el proceso formador del carácter del estudiante? ¿Por qué la comunicación visual es relevante? ¿Debe ir en congruencia con la cosmovisión y filosofía educativa cristiana adventista?.

\section{Educación: una comunicación significativa}

Uno de los procesos más estudiados, debido a su complejidad y alcances, es el proceso comunicativo. Algunos estudiosos han definido a la comunicación como un conjunto de medios, instrumentos y recursos que permiten transmitir ideas, experiencias, sentimientos, actitudes e imágenes de una persona, generación o sociedad a otra. De tal manera que como siempre está presente en las acciones humanas, se constituye en un elemento valioso para la convivencia humana.

Obviamente, al hablar de la comunicación y de lo que involucra, no podemos dejar de mencionar las diversas propuestas respecto a su fórmula con elementos identificados por Berlo, Laswell, Shannon y Weaver, Schramm, y otros teóricos, donde, en síntesis y conjugadamente, se puede mencionar a la fuente, el emisor, el medio, el mensaje, el receptor y el contexto.

No obstante, al revisar el significado etimológico de la comunicación, encontramos que se trata de una acción que busca poner algo en común entre el 'comunicador' y el agente 'comunicado'. Entonces, si la comunicación es utilizada para influir en alguien, es necesario que existan más elementos o factores que posibiliten la retroalimentación y asimilación del mensaje. Así, se puede resaltar la participación de: (a) una intención o propósito; (b) un elemento común; (c) una acción interpretativa del mensaje y; (d) un conocimiento asimilado.

Pero, ¿qué tiene que ver esto con la labor educadora de los docentes adventistas? y ¿cuál es el vínculo de la comunicación con la educación? Ya hemos mencionado que la comunicación es la herramienta indispensable para el logro de las distintas actividades y funciones humanas. La educación, entendida como "el desarrollo armonioso de las facultades físicas, mentales y espirituales" (White, 2008, p. 9) también necesita de la comunicación para lograr su finalidad. Así, en los procesos educativos no pueden faltar las formas e intenciones comunicativas. Planteamos que los docentes deben 
comprender que, para estar inmersos en la educación "más ennoblecida", requieren de una comunicación significativa, que solo puede ser otorgada por el Creador de la comunicación, quien conoce a la perfección sus elementos y el secreto de su funcionamiento. Explicando un poco más; si "la mente del hombre se pone en comunión con la mente de Dios; lo finito con lo infinito; el efecto que tiene esta comunión con el cuerpo, la mente y el alma sobrepuja toda estimación" (White, 2008, p.10).

Ya que existe una estrecha relación entre la comunicación y la educación, podemos identificar algunos elementos valiosos en su proceso que coadyuven a comprender la delicadeza y seriedad de su naturaleza. Líneas arriba mencionamos algunos de ellos, y podemos relacionarlos con las acciones comunicativas del docente cuando se participa del proceso de enseñanza-aprendizaje desarrollado en el aula.

Toda acción comunicativa persigue un objetivo, es decir, no se da de balde. A eso le hemos llamado el elemento intención o propósito. Para teóricos de la comunicación como Martínez Albertos (1977), "toda comunicación humana lleva consigo, de forma clara o bien oculta -a veces oculta incluso para el mismo sujeto emisor del mensaje-, una cierta intencionalidad de captación o influencia sobre los otros. No hay comunicaciones humanas gratuitas. Con toda comunicación se busca siempre, en mayor o menor grado, influir a un sujeto o grupos de sujetos. Influir significa informar. Esta información supone un cambio, entendido como una actitud crítica o favorable a la formación recibida" (p. 15). Por consiguiente, debemos preguntarnos: ¿Cuál es el propósito de la educación adventista? ¿Qué es lo que se desea comunicar a los estudiantes? White (2008) menciona que los docentes, a través de las lecciones impartidas, deben contribuir en la formación de un carácter piadoso para asemejarlos a la imagen original otorgada por el Creador. Eso implicaría que cada vez que transfieren mensajes a sus estudiantes, deben hacerlo con el propósito que caracteriza a esta educación.

Otro es el elemento común. Según Umberto Eco (1985) es posible una comunicación si existe un código común entre el emisor y el receptor. Para el filósofo italiano no existe un proceso comunicativo sin significación. O sea que se precisa de un sistema de significación, donde se descifre el signo, desde la forma más simple del lenguaje natural, hasta la más compleja y elaborada por el hombre. Por ello, es necesario que los docentes identifiquen, en sus interacciones con los estudiantes, un código que los una y que sea conocido tanto por el emisor como por los receptores. Solo así se podrá dar paso a la interpretación adecuada del código. 
Entonces, es allí donde cobra importancia la acción interpretativa del mensaje. En esta etapa cobra relevancia la palabra 'decodificación' propuesta por David Berlo (2004) para explicar la complejidad del proceso de la comunicación. Aquí el sujeto 'decodificador' descifra los códigos recibidos en el contenido del mensaje. Para el proceso educativo, los enseñantes y educandos también decodificarán los mensajes trasmitidos en cada sesión de aprendizaje.

Por último, nos referimos al conocimiento asimilado, que deriva de la decodificación y aprehensión del mensaje más significativo para el decodificador. Este elemento se convierte en el punto de partida para la 'encodificación' de un muevo mensaje que luego será transmitido por el 'encodificador'. Es una acción valiosa e inevitable para la retroalimentación o feedback. Luego de las enseñanzas dadas por los docentes, se espera que los estudiantes adquieran nuevos conocimientos, presentados desde su propia individualidad y que serán retransmitidos en el accionar educativo. Por su parte, los educadores también deberán asimilar conocimientos de la fuente principal del conocimiento para luego compartirlas con sus estudiantes. Con firmeza se declara en el libro "La educación" que: "puesto que Dios es la fuente de todo conocimiento verdadero, el principal objeto de la educación es dirigir nuestra mente a la revelación que hace de sí mismo" (White, 2008, p. 11).

En esta primera parte, proponemos los siguientes modelos donde se identifican los elementos del proceso de comunicación significativa que debe considerar el docente antes de enseñar y el que debe aplicar en el momento de la enseñanza y generación del aprendizaje.

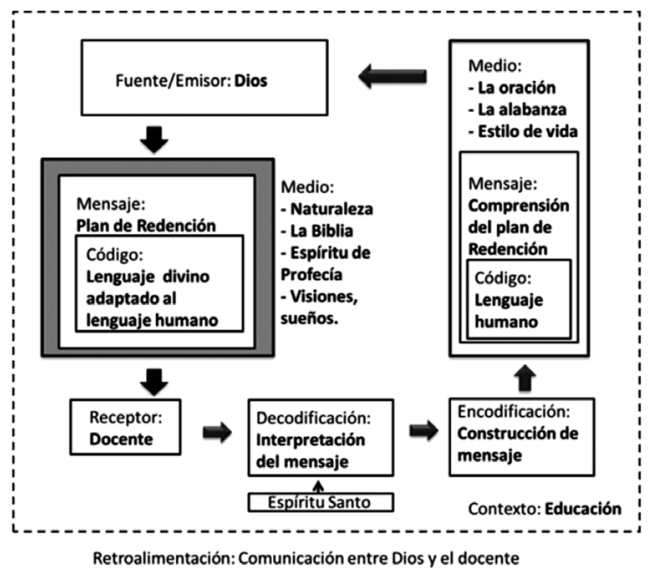

Modelo 1. Educación y comunicación para el docente 


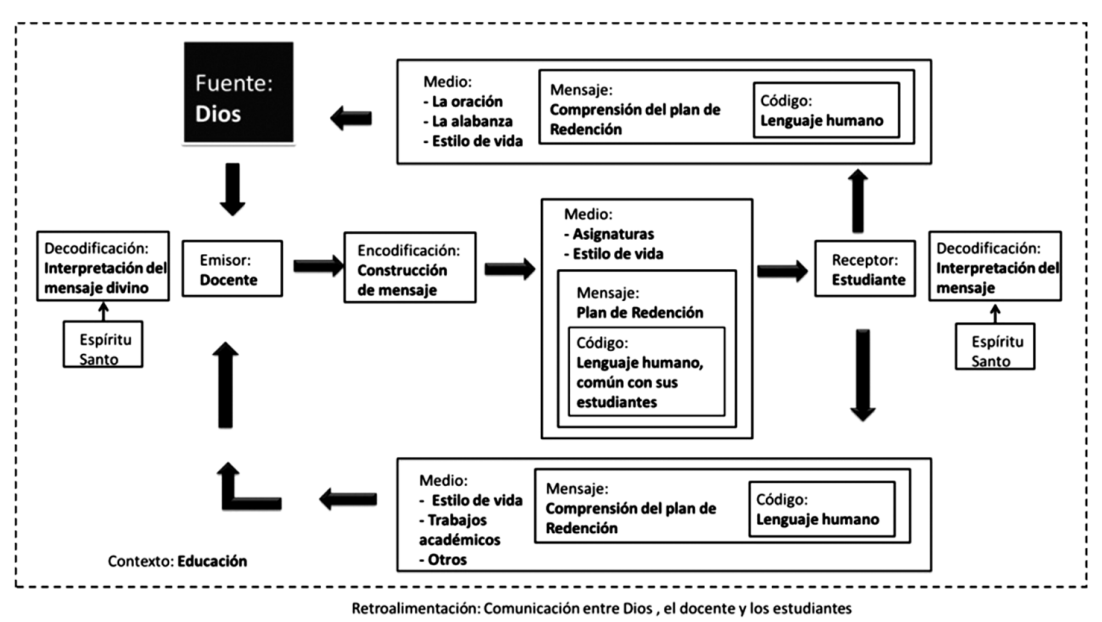

Modelo 2. Educación y comunicación para el docente y el estudiante

\section{La imagen visual en la educación}

En todo proceso comunicativo intervienen aspectos verbales y no verbales, algunas veces separados, otras, juntos; pero con la única finalidad de colaborar con la transmisión de los mensajes, de acuerdo a las diversas situaciones y contextos. "En realidad, lo visual y lo verbal ejercen un poder combinado, es decir, el mayor efecto se obtiene cuando ambos elementos trabajan reforzándose mutuamente" (León, 1992, p. 105).

En este artículo se pretende analizar a la imagen y su función dentro de las actividades educativas. Como se sabe, los docentes utilizan una diversidad de recursos y estrategias para reafirmar en los educandos los contenidos de las asignaturas y otras enseñanzas. Uno de los recursos más utilizados en las sesiones de aprendizaje es la imagen, ya que "una característica básica de ella es que sirve para facilitar la comprensión o interpretación de las ideas" (Peña, 2007, p. 86).

La imagen o las imágenes visuales son elementos que forman parte de la comunicación visual. Esto se refiere a la forma de expresar un pensamiento, idea, emoción o cualquier mensaje a través de los recursos gráficos que puedan ser percibidos por el sentido de la vista. Se pone, en común, un mensaje que ingresa por los ojos. Para Costa (2006), "las imágenes son estímulos poderosos para la mente humana. Esos poderes han sido 
ampliamente reconocidos y utilizados como instrumentos de persuasión y dispositivos de poder, desde mucho antes de la invención de los medios mecánicos de reproducción audiovisual". Además, Costa explica, citando a Gombrich, que "hay algo en lo cual la imagen visual tiene la primacía absoluta en materia de aprendizaje: su poder de activación de la atención o las emociones del observador" (p. 155).

Pero, ¿qué otras explicaciones se pueden tener de las imágenes? y ¿cuál es la utilidad que llama la atención del ser humano para poder expresar sus mensajes? Según el diccionario de la Real Academia Española, en su vigésima segunda edición, el sustantivo imagen proviene del vocablo latín imago. Una de sus acepciones la describe como figura, representación, semejanza y apariencia de algo. Eso significa que al hacer uso de las imágenes visuales se pretende relacionarlo con determinadas ideas, emociones o sentimientos. Para Peña (2007) las imágenes representan la realidad y deben ser entendidas no solo como algo físico cuando está sobre un soporte. Es decir, no hay que verlas como mensajes en sí, sino también como medios que transmiten la realidad de algo a los sujetos observadores; así "la imagen es un mapa que combina la realidad con nuestra idea de la realidad (...) la percepción, la cognición, la subjetividad y la objetividad, se combinan en las imágenes para darnos relaciones figurativas" (Catalá, 2005, p. 25).

Es importante comprender el rol de la imagen, más allá de su definición de una "figura utilizada en cualquier fase del proceso de reproducción y preparación de los materiales de impresión" (Peña, 2007, p. 83), "porque están impregnadas de un punto de vista; de un doble punto de vista si se quiere, puesto que contienen por lo menos una mirada, y además son ellas mismas miradas indefectiblemente" (Catalá, 2005, p. 30). Por consiguiente, detrás de cada imagen hay una idea, un pensamiento. Esta premisa, llevada a la labor del docente en las instituciones educativas adventistas, permite relacionar la cosmovisión bíblico-cristiana con las figuras e imágenes.

\subsection{Las imágenes y el trasfondo bíblico de la filosofía de la educación adventista}

La educación adventista tiene su fundamento en la Biblia, entonces vale la pena analizar de ella algunos ejemplos de situaciones donde las imágenes o representaciones visuales cumplieron una labor comunicativa entre Dios y su pueblo. Durante su peregrinación en el desierto, Moisés recibió indicaciones para la construcción de un santuario de adoración a Jehová (Éxodo 25:8). Este incluiría mobiliarios y utensilios con figuras y 
detalles visuales que representarían la santidad y pureza en la relación con la divinidad. Además, con la participación de las ofrendas, ritos y sacrificios, los israelitas comprenderían el plan de redención a favor de la humanidad. Por consiguiente, todo lo que ellos veían en ese sagrado recinto, los llevaría a pensar en el trasfondo espiritual de las representaciones visuales.

También, es interesante identificar cómo Dios, desde la creación, ha utilizado los mensajes visuales para enseñar al hombre su naturaleza, obra y carácter. Podemos preguntarnos ¿por qué Dios ha utilizado la imagen visual para transmitir y comunicar sus mensajes? Como Creador del hombre, sin duda, conoce el funcionamiento del cerebro humano que Él formó; por esa razón sabe qué medios son útiles para la comprensión de los mensajes. Y se sabe que "lo visual afecta en mucha mayor medida a la memoria, esto es, que lo visual se almacena con mayor intensidad, y por tanto, es posible que sea recordado y reconocido" (León, 1992, p. 101). Pero, ¿qué cosas son más fáciles de ser recordadas? Hay que reiterar que, en un proceso de comunicación, es imprescindible poner algo en común, y "cuando un individuo percibe algo como familiar se ve más favorablemente dispuesto hacia ese objeto y, por el contrario, desconfiamos de aquello que no conocemos" (p. 37). De esa manera, el relato bíblico de la serpiente de bronce (Números 21:9), ratifica que las figuras 'familiares' pueden facilitar la comprensión del mensaje. Sin embargo, el hecho de que "la imagen representa un acto comunicativo" (Peña, 2007, p. 83) y que figura un mensaje que intencionalmente se desea transmitir, no fue siempre recordado por todos los israelitas.

En este contexto, el docente adventista puede darse cuenta de que el uso de recursos visuales al comunicar un mensaje con trasfondo espiritual y religioso es un asunto delicado. Por eso, exige mayores esfuerzos del educador para la selección de imágenes y figuras que serán mostradas y percibidas en el aula de clase. Knight (2002) declara que "los educadores cristianos deben considerar sus sistemas educativos como esfuerzos mancomunados erigidos sobre el fundamento de la filosofía cristiana. Más allá del fundamento filosófico, toda la superestructura del sistema educativo debe construirse con materiales y procesos que estén en armonía con el cristianismo". Y añade que "lo que se necesita en la instituciones cristianas es un continuo programa de análisis profundo, evaluación y corrección de las prácticas educacionales a la luz de las creencias filosóficas básicas" (p. 174).

Volviendo a los ejemplos bíblicos, el caso mencionado en el libro de Números, donde "Jehová habló a Moisés diciendo: Habla a los hijos de Israel, y diles que se hagan franjas en los bordes de sus vestidos, por sus generaciones; 
y pongan en cada franja de los bordes un cordón azul" (15:37-38) permite enfatizar que "la imagen representa un acto comunicativo completo, porque además de permitir la comunicación de una forma determinada, contribuye a la transmisión de información" (Peña, 2007, p. 83). Es decir, estas indicaciones dadas a los israelitas tenían la intención de reforzar en ellos un mensaje enseñado desde generaciones pasadas. La finalidad del mensaje de esa representación visual es aclarada por Dios cuando expresó: "Y os servirá de franja, para que lo veáis y os acordéis de todos los mandamientos de Jehová, para ponerlos por obra" (Números 15: 39).

Todas estas situaciones pueden permitir a los docentes adventistas reflexionar en el uso de las figuras e imágenes visuales dentro de un proceso educativo, así como las implicancias de sus mensajes. De esa forma, el tema de la Integración de la Fe en el Aprendizaje es oportuno. ¿Cómo utilizar recursos visuales sin relacionarlos con la cosmovisión bíblico-cristiana? Aunque para algunos educadores y pensadores adventistas, el término Integración de la Fe en la Enseñanza o en el Aprendizaje (IFE, IFA) no es el más adecuado, lo relevante del asunto es que un docente que esté inmerso en un sistema educativo con una filosofía educativa adventista, tendrá que educar, en cada sesión de aprendizaje -y aun más allá de eso- practicando la filosofía mencionada. Desde la perspectiva de Bouvet de Korniejczuk (2005) "una cosmovisión cristiana se concentra solo cuando los docentes integran esos principios en la práctica al nivel del aula y promueven su integración en la vida de los alumnos" (p. 33).

Entonces, ya sea que se mencione la IFE, la IFA, o como Gangel prefiera la 'Armonía' de la Fe en el Aprendizaje, por su "significado de fusión, correlación, conexión, asociación y aplicación" (Bouvet de Korniejczuk, 2005, p.24), en una sesión de aprendizaje, cada recurso gráfico utilizado puede estar relacionado con el pensamiento cristiano, aunque la materia enseñada no sea Biblia, Religión o Formación Cristiana. En este contexto, se hace más trascedente la conexión de la fe en las actividades educativas formales. Asimismo, reafirmando esta idea, el pensador adventista George Knight (2002) enfatiza que "las prácticas educativas están condicionadas por las creencias religiosas (...) al aplicar las creencias filosóficas a las prácticas educativas hay tanto libertad de elección como responsabilidad individual" (p. 206). Dentro del sistema educativo adventista, todos los agentes educativos deben asimilar la idea de que "Dios quiere revelarse al mundo a través de las instituciones educativas" (Bouvet de Korniejczuk, 2005, p.90).

Por su parte, el libro "Pedagogía adventista" (2009) señala que los educadores cristianos deberán aplicar métodos que faciliten el aprendizaje de 
los estudiantes. Además, "los medios y los recursos tecnológicos utilizados por el profesor en el salón de clases también resultan ser un importante elemento que debe ser considerado aquí, pues son mucho más que instrumentos que auxilian al profesor en el proceso de enseñanza-aprendizaje" (p. 69). Entre los medios que menciona, como aliados para el docente en la presentación de los contenidos en clase, se encuentran: el libro didáctico, el cuadernillo didáctico, el pizarrón y los proyectores multimedia.

Por lo expuesto, hasta esta parte, podemos decir que en cada acción del docente, orientada al aprendizaje y desarrollo integral del estudiante, debiera considerarse, con cuidado y responsabilidad, la relación entre la imagen y el discurso que va junto a ella, en un contexto específico de educación formal, porque como menciona Catalá (2005), al citar al Argullol, nada hay más erróneo que el habitual prejuicio de nuestra tradición que separa la "cultura de la imagen" de la "cultura de la palabra". Es sorprendente comprobar la necesidad mutua de la palabra y de la imagen en la generación del conocimiento. Estos conocimientos pueden ser transmitidos en una comunicación visual, a través de recursos estáticos y/o dinámicos. Entre los estáticos, los más empleados son los carteles, las gigantografías, los pizarrones, los rotafolios, otros. Entre los dinámicos, se utilizan las presentaciones de Power Point y otros de presentación multimedia, los gráficos animados, los audiovisuales y otros. También proponemos que cada educador adventista analice, considere y reflexione sobre la utilidad e impacto comunicativo que pueden lograr otras presentaciones gráficas o representaciones reales visuales que se muestran en el aula y son percibidas por los estudiantes. Así, no solo impactará el mensaje de las imágenes plasmadas y proyectadas con los recursos didácticos mencionados, sino que también harán su parte, la imagen física del aula y la presentación física del docente.

Por ello, creemos que sería oportuno que los educadores adventistas mantengan vigente en su pensamiento de educadores que deben reflejar la imagen del Creador y que "cada ser humano creado a la imagen de Dios, está dotado de una facultad semejante a la del Creador: la individualidad, la facultad de pensar y hacer" (White, 2008, p. 11). Asimismo, "la mejor vía para los educadores y los sistemas educativos consiste en examinar individualmente sus propias creencias básicas, en términos de la realidad, la verdad y el mérito, y luego estructurar conscientemente una filosofía personal de la educación sobre esa plataforma. Al realizar esta tarea el educador cristiano puede elegir utilizar las percepciones de las filosofías y teorías que sean apropiadas y válidas" (Knight, 2002, p. 174). 


\subsection{El impacto de la imagen visual en la educación adventista}

Si bien es cierto que la imagen visual, en un determinado contexto y situación, transmite un mensaje a sus perceptores, el mensaje, según Berlo (2005) es el verdadero producto físico del emisor-encodificador. $Y$, siendo que ese producto físico es visual, está contenido por elementos que están asociados para lograr expresar el significado. Entre estos destacan: "el significado, que es el contenido informativo que se transmite" y "el significante, que es la forma (sonidos, trazos, gestos, colores) para expresar el significado" (Peña, 2007, p. 84).

Desde las diversas funciones de la imagen, identificadas por Peña (2007) es posible establecer las formas cómo influirán en los sujetos que la perciben. De esa manera, puede analizarse su impacto informativo, estético, descriptivo y emotivo. Todo ello, para contribuir en la persuasión de determinados mensajes.

\subsubsection{Impacto informativo-persuasivo}

"La imagen tiene como objetivo transmitir alguna información. En esta función sirve de soporte a un contenido o comunica una situación específica" (Peña, 2007, p. 86).

Hay que aclarar que si la imagen se ayuda de un código, un texto y un contexto, podrá transmitir cabalmente un mensaje. Para Dondis y Beramendi (1978) es necesario el aprendizaje de una gramática de las imágenes, solo así se entenderá mejor la cultura que se recibe y percibe. "Además de transmitir el mensaje específico que la ha generado, también contribuye a la construcción de la cultura en el más amplio sentido de la palabra, promoviendo modelos de pensamiento y conducta que influyen en la manera en que la gente se relaciona con otros mensajes, con las cosas y con otra gente" (1999, Frascara, p. 13). En el caso de la educación adventista, la cultura de una cosmovisión cristiana también debería ser informada, por medio de los recursos visuales que ayudan al docente a enseñar a los alumnos. De allí que no es compatible la muestra de imágenes cuyo contenido difiera con la cosmovisión bíblicocristiana.

También se resalta el papel del color en una acción comunicativa. Para Eco (1985) el color no es un asunto fácil de interpretar, ya que puede informar muchas cosas, dependiendo la cultura donde se lo decodifique. "El color también puede cumplir una función directamente persuasiva, es decir, 
puede utilizarse para formar o alterar los juicios de los receptores acerca de una determinada cuestión y objeto" (León, 1992, p. 111).

Así que "la función informativa es primordial en el color, permite una aprehensión más natural de los objetos. A nivel de la composición de la imagen, el color permite privilegiar la importancia de algunas áreas en detrimento de otras" (Bedoya y León, 2003, p. 118). "El color cumple su papel no solo por sí mismo, sino por su asociación con aquellas imágenes que lo contienen. Así el color verde es ampliamente utilizado en cuanto asociado a la naturaleza, lo que forma el contexto persuasivo para muchos objetos apoyados en el eje de la 'naturalidad'. Prácticamente todas las emociones, todos los símbolos y conceptos podrían ser asociados a un color determinado: la masculinidad y la femineidad, el carácter de lo revolucionario, la paz, el conservadurismo, la realeza, el bienestar, la tierra, el calor, etc." (León, 1992, p. 112).

\subsubsection{Impacto estético}

"La imagen está particularmente cuidada en su aspecto visual. En esta función, la elaboración de la imagen es fundamental y crítica, pues la distorsión de su forma, ya sea por falta de dominio de la técnica de dibujo o desconocimiento de los códigos visuales, puede ser desagradable a la vista del receptor" (Peña, 2007, p. 86).

La Biblia declara que Dios, al hacer uso de su prerrogativa de Creador, "todo lo hizo hermoso en su tiempo" (Eclesiastés 3:11). Es decir, que la estética es un factor trascendente en la comunicación. George Knight (2002) subraya que "el hecho de que Dios, creara un mundo de belleza sugiere que el entorno educativo total tiene implicaciones estéticas (...) La educación cristiana debería ayudar a los alumnos a estar conscientes del papel de la estética, tanto en la vida diaria como en el ámbito de la "cultura superior". Eso indicaría que "el valor estético está más ligado a la educación que la mayor parte de las personas reconocen al principio." (p. 205).

Por tal razón, los docentes debieran contemplar más la naturaleza de la creación de Dios, para que pueda servirles de inspiración y ayuda en la técnica de combinaciones de color y decoración en los recursos visuales que presenta en el aula. "Pueden usarse los colores de modo armónico-situaciones tensas y enérgicas son registradas con colores igualmente enérgicos- o en forma de contraste -una situación débil desde el punto de vista dramático se registra con colores intensos" (Bedoya y León, 200, p. 118). 
También, la estética tiene repercusiones en las conductas éticas. Los estudiantes, que están en un salón de clase que respeta lineamientos estéticos, por lo menos, básicos, manifestarán comportamientos acordes a lo que la armonía que las imágenes visuales les sugieren. Porque, "lo que leemos, vemos, escuchamos y tocamos tienen un efecto en nuestras vidas diarias. Por lo tanto, la estética está en el mismo centro de la vida cristiana" (Knight, 2002, p. 202).

Si "los objetos y decorados cumplen un rol funcional y, además, persuasivo" (León, 1992, p. 114) en el aula destinada para el aprendizaje, se hace necesario que el profesor deba "entender las implicaciones psicológicas y sociológicas, así como las filosóficas, que intervienen en la interacción del ser humano" (Knight, 2002, p. 206). Cada elemento estético complementará el discurso del docente y le relacionará con la naturaleza de su ser. Dios usó la estética en la creación. Por eso "los seres humanos son seres estéticos, y ese lado de su vida y educación no puede ser dejado de lado sin tener consecuencias desfavorables" (Knight, 2002, p. 203).

\subsubsection{Impacto descriptivo}

Una buena imagen explica rápidamente su contenido (Peña, 2007, p. 86). Los docentes al seleccionar las imágenes visuales que mostrarán deben ser cuidadosos en elegir aquellas que tengan una temática tan general, que no distraiga a los estudiantes del tema enseñando; sino que concentre, de ser posible, en una escena visual, el mensaje principal de estudio, o por lo menos que sea el que mejor lo complemente.

Pero, además de las imágenes dinámicas o estáticas, como fotografías, diapositivas, afiches, dibujos y otros, también existen otras imágenes visuales que proyectan los docentes en el momento que ingresan al aula para interactuar con sus educandos. Estas se explican por sí mismas y describen estados emocionales y conductas del profesor. León (1999) refiere que "la expresión de rostro tiene el poder de suscitar en cada uno de nosotros una gran variedad de emociones: ternura, sensualidad, simpatía, aversión, inteligencia, etc." (p. 113). O sea que la comunicación corporal -deliberada o no deliberadamente- describe al educador y tiene una consecuencia inmediata y de reflejo en sus observadores. León añade que "prácticamente para cada mensaje hay un tipo distinto de expresión facial, desde luego, en persuasión predominan las expresiones positivas, admiratorias, seductoras, joviales y de autodominio y seguridad". 
De otro lado, aspectos como la indumentaria de los maestros se convierten en imágenes visuales llamativas para los estudiantes observadores. "El vestuario permite cumplir multitud de funciones significativo-persuasivas: relax, elegancia, deportividad, juventud, madurez, calor, frialdad, autoridad, cercanía, etc. El vestuario añade significado a cada una de las personas" (León, 1992, p. 113). Por ello, debido al impacto del vestido a través de la descripción de quién es el docente, es oportuno citar la sugerencia del Dr. Canale (2012), cuando hace mención de la vestimenta y su relación con el mensaje de una cosmovisión cristiana. "Un cambio radical en lo que se refiere a atraer a las personas no hacia nosotros mismos sino hacia Cristo es coherente con la meta misionera general del discipulado cristiano. En cada cultura los cristianos escogen vestirse en formas que los ayudarán a reflejar a otros sus valores espirituales internos recién descubiertos en Cristo (pp. 136-137).

También, los edificios generan un impacto con la imagen visual que estos describen. Por eso "cuando uno entra en un lugar el cuerpo se empatiza con el ambiente. Hay espacios que denigran y espacios que dignifican; espacios que acentúan lo espiritual, espacios que acentúan lo sensual y espacios que acentúan el poder" (Frascara, 1999, p. 18).

\subsubsection{Impacto emotivo}

La forma y el contenido de las imágenes generan emociones y sensaciones diversas en los sujetos que las perciben. Frascara (1999) alerta hacia el hecho de que "los mensajes emocionales a su vez constituyen una arma de doble filo.

Un mensaje muy emocional puede centrar toda la atención en la emoción" (p. 21). De allí, que el docente debe ser cuidadoso en la selección de los colores que se mostrarán en sus recursos didácticos visuales, además de considerar el tiempo de exposición que tendrán los mismos.

Para Bedoya y León (2003) tanto para las imágenes visuales dinámicas o estáticas el "color marca centros de interés visual. La función expresiva del color conduce a una aprehensión emocional de este. Los sentidos se excitan con el valor cromático añadido, involucrando al espectador con el universo representado (p. 118).

Los significados de los colores pueden generar diversas emociones de acuerdo a factores culturales, ambientales e ideológicos, como se menciona en el siguiente cuadro: 


\begin{tabular}{|l|l|l|l|l|}
\hline Color & Significado & & Color & Significado \\
\hline Rojo & Amor, pasión. & Negro & Tristeza, temor. \\
\hline Amarillo & Optimismo, alegría. & & Anaranjado & Libertad \\
\hline Azul & Serenidad, confianza, frialdad. & Verde & Esperanza \\
\hline Blanco & Paz, calma. & & Marrón & Tranquilidad \\
\hline
\end{tabular}

En el aula de clase, el estudiante es cautivado desde el momento que ingresa a ella. De allí que la forma de su infraestructura, el diseño y decoración impactarán visualmente generando una serie de emociones y sensaciones. Por ejemplo, "hay espacios que calman y espacios que enervan; espacios que nos llevan a épocas edénicas pasadas y espacios que nos invaden agresivamente. Los colores, las formas (...) más la historia personal de nuestras experiencias, contextualizan a nuestra percepción y la cargan de significado, generando una respuesta compleja que integra conocimientos, sentimientos y valores" (Frascara, 1999, p. 17). "Los colores cálidos y enérgicos remiten a una atmósfera exaltada o eufórica; por el contrario, los colores fríos y débiles evocan una atmósfera apagada (Bedoya y León, 2003, p. 119).

Además, como añade Frascara, la disposición del mobiliario en el salón de clase, predispondrá a los estudiantes a ciertos comportamientos que repercutirán en su relacionamiento interpersonal y en su disposición para el aprendizaje.

En relación a lo expuesto, una imagen impactará de diversas formas en las emociones de sus observadores. Por ejemplo, a través del color, el diseño, la forma, el contenido, el tiempo de exposición y la intensidad.

\section{Responsabilidades y desafíos del docente adventista en la integración de la fe en el aprendizaje}

La aplicación y el ejercicio de las funciones docentes son tareas complejas y llenas de responsabilidad. "Tratar con las mentes juveniles es la obra más hermosa en que se hayan empeñado jamás hombres y mujeres. Debe ejercerse el mayor cuidado en la educación de los jóvenes, a fin de variar la manera de instruirlos, con el propósito de despertar las facultades más elevadas y nobles de la mente" (White, 2008, p. 9).

En una época donde el pensamiento posmoderno incursiona en los sistemas educativos humanos, es necesario redescubrir los fundamentos de una filosofía educativa cristiana, a través de la revisión de la Biblia. 
Aunque, para los educadores posmodernistas, ese libro no constituye más de una metanarrativa irreal y fantástica; los maestros adventistas requieren internalizar la idea que "debieran buscar con más fervor aquella sabiduría que Jesús está siempre dispuesto a conceder, pues están tratando con la mente humana en el período más interesante e impresionable de su desarrollo" (White, 2008, 27). Además, comprender que "la enseñanza no consiste en aprender una fórmula para relacionarse con la gente o seguir un plan maestro con el fin de desarrollar un carácter cristiano. Es más bien un arte que demanda pensamiento y acción responsables de parte del educador" (Knight, 2002, p. 206).

De esa forma, los docentes adventistas que "profesan ser cristianos, aprendan diariamente las lecciones de Cristo en la escuela de Cristo" (White, 2008 , p. 253) y "cuando los docentes y estudiantes consagren a Dios alma, cuerpo y espíritu, y purifiquen sus pensamientos por medio de la obediencia a las leyes de Dios, recibirán continuamente una nueva dosis de fuerza física y mental" (p. 255). Para Canale (2012) "se hace evidente que la experiencia de la salvación cristiana requiere una mente clara para comprender las verdades espirituales de Cristo para la vida y las decisiones cotidianas en conformidad con su voluntad" (p. 137). Pero, ¿cómo mantener una mente clara, divorciada de las influencias de una educación secularizada? Uno de los problemas es que "el adventismo se seculariza al adaptar su pensamiento y conducta a los patrones del mundo, un mundo que está distante del Dios de la Biblia" (Canale, 2012, p. 25). Entonces, si hay secularización en los estilos de vida de los adventistas, en un marco eclesial, ¿puede esta problemática identificarse también en las prácticas educativas de los docentes adventistas? Lo expresado por el apóstol Pablo puede describir la naturaleza veleidosa del hombre. Así que si un docente "piensa estar firme, mire que no caiga" (1 Co. 10:12).

Ahora bien, entre las responsabilidades y desafíos que los docentes adventistas deben contemplar, podemos mencionar los siguientes:

a) Identificar la naturaleza de sus contenidos de enseñanza: "Una de las primeras tareas del docente frente a una asignatura es determinar qué va a enseñar y qué no va a enseñar. Esa decisión es crucial, y no solamente está determinada por el nivel de la asignatura, sino por la cosmovisión y las presuposiciones filosóficas, los conocimientos, los gustos del docente y las necesidades del estudiante" (Bouvet de Korniejczuk, 2005, p. 118).

b) Preparar la clase respetando el desarrollo biológico-emocional de sus estudiantes: "Cuanto más joven el estudiante, más cuidadosa la 
selección. No es lo mismo seleccionar contenidos para estudiantes de nivel primario, secundario o universitario" (Bouvet de Korniejczuk, 2005, p. 20).

c) Seleccionar y discriminar adecuadamente los contenidos de enseñanza: "Si el profesor distingue qué contenidos son indispensables, esenciales, tanto él como sus estudiantes verán claramente la importancia que le da a estos. Esta importancia estará marcada por el tiempo que se dedique a ellos, la manera como recurre o utiliza esos contenidos y las aplicaciones que les da (Bouvet de Korniejczuk, 2005, p. 119).

En relación a la selección de imágenes y figuras que mostrará como recurso didáctico, puede considerar lo expresado por Frascara (1999) acerca de que el mundo se enfrenta a una variada serie de propuestas visuales, imágenes, y estas deben aceptarse o rechazarse.

d) Valorar adecuadamente la estética en toda presentación visual: "Si los educadores cristianos pasan por alto o ignoran la importancia de la estética son negligentes en un aspecto crucial de la educación, ya que esa negligencia implica una visión inapropiada de la humanidad y de Dios, según el punto de vista bíblico" (Knight, 2002, p.205).

e) Mantener la mirada en el Divino Maestro: Canale (2012) enfatiza que "puesto que la relación salvífica con Dios se centra en contemplar la faz de Cristo a través del estudio y la comprensión de la Escritura, los discípulos por naturaleza buscan evitar el contemplar y adoptar acríticamente en su pensamiento y estilo de vida las producciones de la cultura humana caída, no importa cuán 'avanzadas y progresistas' puedan ser" (p. 136).

Ya que "educar la mirada no es una tarea sencilla. El apetito del ojo, rara vez se deja domesticar" (Costa, 2006, p. 179), "Ios cristianos evitan la contemplación del mundo y la reemplazan con la contemplación de Cristo" (Canale, 2012, p. 136).

\section{Conclusiones}

- La verdadera educación fue diseñada y planteada por Dios para el beneficio del hombre. En un mundo donde la humanidad ha adquirido una naturaleza pecaminosa, se han desvirtuado muchas creaciones divinas, entre ellas la educación. Sin embargo, Dios, el verdadero Gran Maestro puede enseñarle a sus hijos docentes en qué consiste la verdadera obra formativa. 
- Las acciones docentes requieren responsabilidad y criterio constantes. Los recursos didácticos utilizados en el proceso de enseñanza-aprendizaje deben guardar coherencia con la filosofía de la educación adventista. El uso de la imagen visual constituye una herramienta persuasiva y ayudadora en la transmisión de una cosmovisión bíblico-cristiana. Toda imagen, en un contexto determinado, comunica un pensamiento.

- La selección de las imágenes visuales es responsabilidad del docente, por consiguiente, debe verificar si estas sirven para comunicar y transmitir el mensaje de la mejor manera posible, si ayudarán en retener la atención de los estudiantes, si contribuye a la complementación del discurso hablado en clase, y si evidencia la valoración que tiene el docente de su cosmovisión cristiana. En consecuencia, el docente deberá analizar cuidadosamente el discurso que se comunica a través de las imágenes proyectadas y mostradas en el aula.

- El docente adventista debe estar alerta ante el bombardeo de ideologías extrañas a la Biblia, para que no desvirtúe su comprensión sobre la verdadera naturaleza de la obra educadora.

Nidia Areli Montalvo Cárdenas Universidad Peruana Unión email: nidiamontalvocardenas@gmail.com

Recibido: 10 de diciembre de 2013 Aceptado: 24 de enero de 2014 


\section{Referencias}

Bedoya, R., León Frías, I. (2003). Ojos bien abiertos. El lenguaje de las imágenes en movimiento. Lima. Fondo del desarrollo editorial Universidad de Lima.

Berlo, David K. (2004). El proceso de la comunicación. Argentina. Editorial El Ateneo.

Bouvet de Korniejczuk, R. I. (2005). Integración de la fe en la enseñanza y el aprendizaje. Montemorelos, NL México. Publicaciones Universidad de Montemorelos.

Canale, F. (2012). ¿Adventismo secular? Cómo entender la relación entre estilo de vida y salvación. Lima. Editorial Imprenta Unión. Publicaciones y Difusión Cultural.

Catalá, J. M. (2005). La imagen compleja: la fenomenología de las imágenes en la era de la cultura visual (Vol. 42). Universidad Autónoma de Barcelona.

Costa, L. M. (2006). Algunas reflexiones sobre el lugar de las imágenes en el ámbito escolar. Educar la mirada: políticas y pedagogías de la imágen, 155-164.

Dondis, D. A., \& Beramendi, J. G. (1978). La sintaxis de la imagen: introducción al alfabeto visual. Editorial Gustavo Gili.

DSA. (2009). Pedagogía adventista. Argentina. Asociación Casa Editora Sudamericana.

Eco, U. "How Culture Conditions the Colours We See", en BLONSKY, Marshall (ed). On signs. Baltimore: John Hopkins University Press, 1985. Trad.: Marcelo Giménez.

Frascara, J. (1999). El Poder de la imagen: reflexiones sobre comunicación visual. Ediciones Infinito.

Gombrich, E. H. "La imagen visual: su lugar en la comunicación”. Debate: Madrid, 2000. http:// coerulea.wordpress.com/2008/01/25/la-imagen-visual-su-lugar-en-la-comunicacion/

Knight, G. (2002). Filosofía y educación. Una introducción a la perspectiva cristiana. Editorial Apia. Colombia.

León, José Luis. (1992). Persuasión de masas. Psicología y efecto de las comunicaciones sociopolíticas y comerciales. Ediciones Deusto S.A.

Martínez Albertos, J. E. (1977). El mensaje informativo. Barcelona. Editorial A.T.E.

Ochoa, C. G. (1986). Imagen y sentido: elementos para una semiótica de los mensajes visuales. Universidad Nacional Autónoma de México, Instituto de Investigaciones Filológicas.

Peña, P. (2007). Diseño publicitario. De la idea al papel. Perú. Esepe Editores.

Santa Biblia. (1960). Sociedades Bíblicas Unidas.

White, E. (2008). La educación. Argentina. Asociación Casa Editora Sudamericana.

White, E. (2008). La educación cristiana. Argentina. Asociación Casa Editora Sudamericana.

White, E. (2008). Conducción del niño. Argentina. Asociación Casa Editora Sudamericana. 